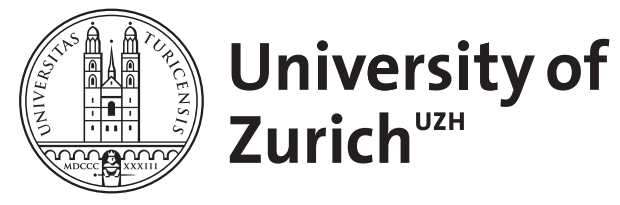

Zurich Open Repository and Archive

University of Zurich

Main Library

Strickhofstrasse 39

CH-8057 Zurich

www.zora.uzh.ch

Year: 2015

Effects of selective estrogen receptor alpha and beta modulators on prepulse inhibition in male mice

\author{
Labouesse, Marie A ; Langhans, Wolfgang ; Meyer, Urs
}

DOI: https://doi.org/10.1007/s00213-015-3935-9

Posted at the Zurich Open Repository and Archive, University of Zurich

ZORA URL: https://doi.org/10.5167/uzh-120360

Journal Article

Accepted Version

Originally published at:

Labouesse, Marie A; Langhans, Wolfgang; Meyer, Urs (2015). Effects of selective estrogen receptor alpha and beta modulators on prepulse inhibition in male mice. Psychopharmacology, 232(16):2981-2994.

DOI: https://doi.org/10.1007/s00213-015-3935-9 


\section{Effects of selective estrogen receptor alpha and beta modulators on prepulse inhibition in male mice}

Marie A. Labouesse ${ }^{1, *}$, Wolfgang Langhans ${ }^{1}$, Urs Meyer ${ }^{1,2}$

1Physiology and Behavior Laboratory, ETH Zurich, Schwerzenbach, Switzerland.

${ }^{2}$ Institute of Pharmacology and Toxicology, University of Zurich-Vetsuisse, Zurich, Switzerland.

*Correspondence: $\quad$ Marie A. Labouesse

Physiology and Behavior Laboratory

ETH Zurich

Schorenstrasse 16

8603 Schwerzenbach

E-Mail: marie-labouesse@ethz.ch

Tel.: +4144655 74 50; Fax.: +41446557206.

\section{Acknowledgements}

We would like to thank Selina Frei for assisting the behavioral experiments. This work was supported by grants from the Swiss National Science Foundation (310030_146217) and the European Union Seventh Framework Program (FP7/2007-2011; Grant Agreement Nr. 259679) awarded to U.M.

\section{Disclosure}

All authors declare that they have no conflicts of interest to disclose. 


\section{Abstract}

Rationale. Multiple lines of evidence suggest that the sex steroid hormone 17- $\beta$ estradiol (E2) plays a protective role in schizophrenia. Systemic E2 enhances prepulse inhibition (PPI) of the acoustic startle reflex, an operational measure of sensorimotor gating known to be impaired in schizophrenia and related disorders. However, the relative contribution of different estrogen-receptor (ER) isoforms in these associations still awaits examination.

Objectives. The present study explored the effects of ER- $\alpha$ and ER- $\beta$ stimulation or blockade on PPI and their functional relevance in an amphetamine-induced PPI deficiency model in male mice.

Methods. Prior to the assessment of PPI, C57BL/6N male mice were injected with the ER- $\alpha$ agonist 4,4',4"'-(4-propyl-[1H]-pyrazole-1,3,5-triyl)trisphenol (PPT), the ER- $\alpha$ antagonist 1,3-bis(4-hydroxyphenyl)-4-methyl-5-[4-(2-piperidinylethoxy)phenol]-1N-pyrozole dihydrochloride (MPP), the ER- $\beta$ agonist 2,3-bis(4-hydroxyphenyl)-propionitrile (DPN), or the ER- $\beta$ antagonist 4-[2-phenyl-5,7-bis(trifluoromethyl) pyrazolo[1,5-a]pyrimidin-3yl]phenol (PHTPP), with or without concomitant amphetamine treatment.

Results. Acute pharmacological stimulation and blockade of ER- $\alpha$, respectively, led to a dose-dependent increase and decrease in basal PPI. In contrast, acute treatment with preferential ER- $\beta$ modulators spared PPI under basal conditions. Pretreatment with either ER- $\alpha$ or ER- $\beta$ agonist was, however, effective in blocking amphetamine-induced PPI disruption.

Conclusions. Our study demonstrates that activation of either ER isoform is capable of modulating dopamine-dependent PPI levels. At the same time, our results suggest that endogenous ER- $\alpha$ signaling may be more relevant than ER- $\beta$ in the regulation of sensorimotor gating under basal conditions.

Key words: amphetamine; dopamine; estradiol; estrogen; prepulse inhibition; schizophrenia; sensorimotor gating 


\section{Introduction}

Schizophrenia is a chronic form of psychotic illness that affects approximately $1 \%$ of the population worldwide (Tandon et al. 2009). A large number of studies have demonstrated the existence of a clear sex dimorphism in the onset, severity and course of the disorder (Häfner et al. 2003). For example, the onset of schizophrenic symptoms occurs on average 1.5 to 4.5 years later in women than in men (Angermeyer and Kühn, 1988; Seeman, 1997). There is also evidence to suggest that psychosis-related symptoms vary across the estrous cycle in women, being most severe when estrogen levels are lowest and after menopause once 17- $\beta$ estradiol (E2) levels are depleted (Angermeyer and Kühn, 1988; Häfner et al. 2003; Seeman, 1997). Interestingly, schizophrenic male and female patients also typically exhibit lower estrogen levels as compared to healthy matched controls (Huber et al. 2001, 2005; Oades and Schepker, 1994). Such epidemiological findings have been taken as evidence for a protective role of the sex hormone estrogen in the etiology and pathophysiology of schizophrenia (Häfner et al. 2003), suggesting that estrogen-related substances could represent relevant targets for the development of new medical treatments.

Besides various other neuropsychological and cognitive deficits, patients with schizophrenia exhibit marked abnormalities in sensorimotor gating (Braff et al. 2001). Prepulse inhibition (PPI) of the acoustic startle reflex is one of the best established translational paradigms that allows assessing sensorimotor gating functions both in humans and in rodent models (Koch and Schnitzler, 1997; Light and Braff, 1999). PPI refers to the reduction of startle reaction to a startle-eliciting stimulus (pulse) when it is shortly preceded by a weak stimulus (prepulse) (Graham, 1975; Hoffman and Searle, 1965). It is an 
operational measure of sensorimotor gating, in which central gating mechanisms protect the processing of the information contained in the initial prepulse from distraction by the subsequent pulse stimulus (Swerdlow et al. 2000). PPI thus reflects the ability to filter or gate intrusive sensory-motor information. Disruption of such filtering mechanisms can result in central stimulus overload and associated dysfunctions in allocating the limited brain resources to only the most important stimuli encountered in the environment, and such abnormalities appear to be a core deficit in psychosis-related disease (Braff et al. 2001).

Converging evidence from clinical investigations in humans and experimental studies in rodents indicate that E2 administration can enhance PPI performance, when administered acutely (Van den Buuse and Eikelis, 2001) or chronically (Gogos and Van den Buuse 2004; Gogos et al. 2006, 2010, 2012). Such investigations have, however, largely focused on females, whilst the putative benefits of estrogen-receptor (ER)-based ligands for treating schizophrenia-relevant symptoms in males has attained less attention (Arad and Weiner, 2010a,b; Kulkarni et al. 2009, 2011, 2013). Yet, male mice with a genetic deletion of the estrogen-synthetizing enzyme aromatase exhibit reduced PPI levels (Van den Buuse et al. 2003), suggesting that the protective roles of E2 could indeed extend to the male sex. It thus appears essential to determine whether estrogen-related substances can modulate PPI levels in naïve male rodents because they could provide new targets for future therapeutic strategies for the male schizophrenia population (Kulkarni et al. 2013).

It also remains essentially unknown which ER subtypes are responsible for the beneficial effects of E2 on PPI. The two main receptors for E2 are ER- $\alpha$ and ER- $\beta$, both of which are expressed at the cellular membrane and in the cytosol (Heldring et al. 2007). 
Binding of membrane ER- $\alpha$ and ER- $\beta$ results in rapid, non-genomic activation of intracellular pathways, whereas activation of cytosolic ER- $\alpha$ and ER- $\beta$ leads to translocation of the ERs to the nucleus and subsequent genomic effects via gene transcription.

In the present study, we used pharmacological approaches to explore the relative contribution of ER- $\alpha$ and ER- $\beta$ in the modulation of PPI in male mice. In a first series of investigations, we studied the effects of acute systemic treatment with ER isoform-selective agonists or antagonists on basal PPI. In a second series of experiments, we explored the effects of these compounds on amphetamine (AMPH)-induced PPI disruption, an established model of dopamine-dependent attenuation of sensorimotor gating (Braff et al. 2001, Swerdlow et al. 2000). To modulate the ER- $\alpha$ subtype, we used the ER- $\alpha$ agonist 4,4',4"'-(4-propyl-[1H]-pyrazole-1,3,5-triyl)trisphenol (PPT) and the ER- $\alpha$ antagonist 1,3bis(4-hydroxyphenyl)-4-methyl-5-[4-(2-piperidinylethoxy)phenol]-1N-pyrozole-dihydrochloride (MPP). Both modulators are known to have a more than 200 -fold selectivity for ER- $\alpha$ over ER- $\beta$ (Harrington et al. 2003, Stauffer et al. 2000). To modulate the ER- $\beta$ subtype, we used the ER- $\beta$ agonist 2,3-bis(4-hydroxyphenyl)-propionitrile (DPN) and the ER- $\beta$ antagonist 4-[2-phenyl-5,7-bis(trifluoromethyl) pyrazolo[1,5-a]pyrimidin-3-yl]phenol (PHTPP). DPN and PHTPP show a 70- and 36-fold selectivity, respectively, for ER- $\beta$ over ER- $\alpha$ (Compton et al. 2004, Meyers et al. 2001). All ER-ligands used in the present study have previously been shown to reach the brain and exert central effects in rodents (Dillon et al., 2013; Grassi et al. 2013; Harris et al. 2002; Le Saux and Di Paolo, 2006; Lund et al. 2005; Saleh et al., 2013; Santollo and Eckel, 2009; Santollo et al. 2007, 2010). 


\section{Methods}

\section{Animals}

Male C57BL/6N mice were obtained from Charles River (Sulzfeld, Germany) at the age of 9-10 weeks. Testing began after 2 weeks of acclimatization to the new animal holding room that was temperature and humidity controlled (21 $\pm 21 \mathrm{C}, 55 \pm 5 \%)$ with a 12 -h light and 12-h dark cycle (lights off at $0800 \mathrm{~h}$ ). All animals had ad libitum access to water and food (Kliba 3436, Provimi Kliba NAFAG, Kaiseraugst, Switzerland) and were kept in groups of 2-5 animals per cage throughout all experimentation. Behavioral testing was always carried out during the dark phase of the diurnal cycle.

All procedures had been previously approved by the Cantonal Veterinarian's Office of Zurich and are in agreement with the principles of laboratory animal care in the Guide for the Care and Use of Laboratory Animals (National Institutes of Health Publication No. 8623, revised 1985). All efforts were made to minimize the number of animals used and their suffering.

\section{Prepulse inhibition of the acoustic startle reflex}

Sensorimotor gating was assessed using the paradigm of prepulse inhibition (PPI) of the acoustic startle reflex. The apparatus consisted of 4 startle chambers for mice (San Diego Instruments, San Diego, CA) as fully described elsewhere (Meyer et al. 2005). In the demonstration of PPI of the acoustic startle reflex, the animals were presented with a series of discrete trials comprising a mixture of 4 trial types. These included pulse-alone trials, prepulse-plus-pulse trials, prepulse-alone trials, and no-stimulus trials in which no discrete stimulus other than the constant background noise was presented. The pulse and 
prepulse stimuli used were in the form of a sudden elevation in broadband white noise level (sustaining for 40 and $20 \mathrm{~ms}$, respectively) from the background (65 $\left.\mathrm{dB}_{\mathrm{A}}\right)$, with a rise time of $0.2-1.0 \mathrm{~ms}$. In all trials, 3 different intensities of pulse $\left(100,110\right.$, and $\left.120 \mathrm{~dB}_{\mathrm{A}}\right)$ and 3 intensities of prepulse $\left(71,77\right.$, and $83 \mathrm{~dB}_{\mathrm{A}}$, which corresponded to 6,12 and $18 \mathrm{~dB}_{\mathrm{A}}$ above background, respectively) were used. The stimulus-onset asynchrony of the prepulse and pulse stimuli on all prepulse-plus-pulse trials was $100 \mathrm{~ms}$ (onset-to-onset).

The protocol used for the PPI test was extensively validated in our laboratory before (e.g., Labouesse et al. 2013, Vuillermot et al. 2010). A session began with the animals being placed into the Plexiglas enclosure. They were acclimatized to the apparatus for 2 min before the first trial began. The first 6 trials consisted of 6 startle-alone trials; such trials served to habituate and stabilize the animals' startle response and were not included in the analysis. Subsequently, the animals were presented with 10 blocks of discrete test trials. Each block consisted of the following: 3 pulse-alone trials $\left(100,110\right.$, or $\left.120 \mathrm{~dB}_{\mathrm{A}}\right), 3$ prepulse-alone trials $\left(+6,+12\right.$, or $+18 \mathrm{~dB}_{\mathrm{A}}$ above background), 9 possible combinations of prepulse-plus-pulse trials ( 3 levels of pulse $\times 3$ levels of prepulse), and 1 no stimulus trial. The 16 discrete trials within each block were presented in a pseudorandom order, with a variable interval of $15 \mathrm{~s}$ on average (ranging from 10 to $20 \mathrm{~s}$ ). For each of the 3 pulse intensities $\left(100,110\right.$, or $\left.120 \mathrm{~dB}_{\mathrm{A}}\right)$, PPI was indexed by percent inhibition of the startle response obtained in the pulse-alone trials by the following expression: $100 \% \times(1-[$ mean reactivity on prepulse-plus-pulse trials/mean reactivity on pulse-alone trials]), for each animal, and at each of the 3 possible prepulse intensities $\left(+6,+12\right.$, or $+18 \mathrm{~dB}_{\mathrm{A}}$ above background). 


\section{Drug preparation and administration}

A first cohort of male mice $(N=24)$ was used to study the effects of ER- $\alpha$ selective modulators on basal PPI. All animals in this cohort first underwent an initial baseline PPI test without any drug treatment. This served to match the subsequent drug conditions according to their baseline PPI scores. One week after the baseline PPI test, the animals were treated with the ER- $\alpha$ selective agonist PPT (Sigma-Aldrich, Buchs, Switzerland) or corresponding vehicle (VEH) solution $60 \mathrm{~min}$ before PPI testing. While several experimental reports have documented the effective impact of E2 on PPI after a $30 \mathrm{~min}$ pre-treatment time (Van den Buuse and Eikelis, 2001), other studies have provided evidence for the notion that striatal dopamine levels peak approximately 60-90 min after systemic E2 administration (Becker and Rudick, 1999), thus providing experimental justification for the choice of a 60 -min pretreatment time. This timepoint also allowed to target both (and perhaps equally important) genomic and non-genomic signaling mechanisms of ER-based drugs. PPT was dissolved in sterile $\mathrm{NaCl}$ containing $10 \%$ ethanol and was administered at a dose of $0(=\mathrm{VEH} ; N=8), 1(N=8)$, or $10 \mathrm{mg} / \mathrm{kg}(N=8)$.

After a drug wash-out period of 1 week, the same animals were used to study the effects of the ER- $\alpha$ selective antagonist MPP (Sigma-Aldrich, Buchs, Switzerland) relative to VEH treatment, thereby counterbalancing the previous drug (PPT) history. To this end, we included the same amount of animals (one third) from each previous drug treatments (namely VEH, PPT-1 and PPT-10) into each of the newly formed groups (namely VEH, MPP20 and MPP-200), so as to control for possible carry-over effects of previous drug exposures. MPP was dissolved in sterile $\mathrm{NaCl}$ containing $10 \%$ ethanol and was administered at a dose of $0(=\mathrm{VEH} ; N=8), 20(N=8)$, or $200 \mu \mathrm{g} / \mathrm{kg}(N=8) 60 \mathrm{~min}$ before 
PPI. The doses of MPP were chosen based on previous studies (Bliedtner et al. 2010; Lund et al. 2005; Santollo and Eckel, 2009; Santollo et al. 2007).

A second cohort of male mice $(N=24)$ was used to investigate the effects of selective ER- $\beta$ modulators on basal PPI. Again, all animals in this cohort were first subjected to an initial baseline PPI test without any drug treatment in order to match the subsequent drug conditions according to their baseline PPI scores. One week after this baseline test, the animals were treated with the ER- $\beta$ selective agonist (DPN) (Tocris Bioscience, Bristol, UK) or corresponding VEH solution 60 min before PPI testing. DPN was dissolved in sterile $\mathrm{NaCl}$ containing 40\% ethanol and was administered at a dose of $0(=\mathrm{VEH} ; N=8), 1(N=8)$, or 10 $\mathrm{mg} / \mathrm{kg}(N=8)$. Although we cannot entirely exclude the possibility that the $40 \%$ ethanol vehicle solution (equivalent to a $1.5 \mathrm{~g} / \mathrm{kg}$ ethanol dose) could functionally interact with DPN to modulate PPI or startle, similar doses of ethanol failed to modulate PPI and startle in other experimental investigations conducted in C57BL/6 mice (Bowers et al. 2005; Lewis and Gould, 2003; Owens et al. 2003), suggesting that the vehicle solution chosen for this particular study would not represent confounders for the detection of primary experimental readouts of interest. After a drug wash-out period of 1 week, the same animals were used to study the effects of the ER- $\beta$ selective antagonist PHTPP (Tocris Bioscience, Bristol, UK) relative to VEH treatment, thereby counterbalancing the previous drug (DPN) history. PHTPP was dissolved in corn oil and was administered at a dose of 0 (=VEH; $N=8), 0.4(N=8)$, or $4 \mathrm{mg} / \mathrm{kg}(N=8) 60 \mathrm{~min}$ before PPI testing.

Two additional cohorts of male mice $(N=32$ each $)$ were used to assess the capability of the selective ER- $\alpha$ modulators (cohort 3) or ER- $\beta$ modulators (cohort 4) to modify AMPHinduced PPI deficits. All animals in cohorts 3 and 4 were first subjected to an initial 
baseline PPI test without any drug treatment in order to match the subsequent drug conditions according to their baseline PPI scores. $D$-amphetamine sulfate (= AMPH; SigmaAldrich, Buchs, Switzerland) was dissolved in sterile $\mathrm{NaCl}$ (= SAL) and administered at a dose of $4.0 \mathrm{mg} / \mathrm{kg} 10 \mathrm{~min}$ prior to PPI testing based on previous mouse studies (Flood et al. 2010).

In cohort 3 , the animals were assigned to 1 of the 4 experimental groups $(N=8$ per group): SAL/VEH, AMPH/VEH, AMPH/PPT or AMPH/MPP. PPT and MPP were dissolved in sterile $\mathrm{NaCl}$ containing $10 \%$ ethanol $(=\mathrm{VEH})$ as described above and administered at a dose of $10 \mathrm{mg} / \mathrm{kg}$ and $200 \mu \mathrm{g} / \mathrm{kg}$, respectively, 60 min prior to PPI testing based on the preceding experiments. The animals in cohort 4 were assigned to 1 of the 4 experimental groups ( $N=8$ per group): SAL/VEH, AMPH/VEH, AMPH/DPN or AMPH/PHTPP. DPN was dissolved in sterile saline containing 40\% ethanol, and PHTPP was dissolved in corn oil as described above. Based on the preceding experiments, DPN and PHTPP were administered at a dose of $10 \mathrm{mg} / \mathrm{kg}$ and $4 \mathrm{mg} / \mathrm{kg}$, respectively, $60 \mathrm{~min}$ prior to PPI testing. Half of the animals assigned to the VEH group in cohort 4 received saline containing $40 \%$ ethanol to match the DPN condition, and the other half received oil to match the PHTPP condition. Preliminary results showed that \%PPI levels did not differ between these two types of VEH conditions (data not shown).

Our administration doses were chosen based on previously published research studies outlining the bioactive effects of ER-selective ligands (PPT, MPP, PHTPP and DPN) and their relative equivalence to the effects of estradiol. The PPT and DPN doses were chosen based on previous studies in rats outlining their effects on uterine weight and sexual behaviors (Frasor et al., 2003, Harris et al., 2002; Lundholm et al. 2008; Mazzucco et al., 2008), 
metabolic parameters (Santollo et al. 2007), fear-and anxiety-related behavior (Lund et al. 2005; Lynch et al., 2014) and brain physiology (Waters et al. 2011). In order to fulfil their biological activity, systemically administered compounds typically require a three-to-fourfold higher dose in mice as compared to rats; for this reason, we multiplied the doses obtained from the rat literature by a factor of 3 to 4 . The doses of MPP were chosen based on published results by Santollo and Eckel (2009) and our own experimental investigations in another model of PPI deficiency (Labouesse, unpublished results). Although there is relatively less literature available regarding the biological effects of PHTPP, we based our choice on available literature relating the ten-fold lower bioactivity of PHTPP relative to MPP on neuroprotection-related variables (Saleh et al. 2013).

The selectivity of these drugs for one receptor subtype over the other have been previously demonstrated by others (Compton et al. 2004; Frasor et al. 2003; Harrington et al. 2003, Kraichely et al. 2000; Meyers et al. 2001, Stauffer et al. 2000; Sun et al. 2002, 2003). The effective doses of PPT, DPN and MPP that significantly modulated PPI or startle in the present study (see Results section), are also known to be equivalent to doses of E2 or estradiol benzoate (EB) previously shown to affect uterine weight or behavioral readouts (Harris et al., 2002; Lynch et al., 2014; Santollo and Eckel, 2009).

All solutions were injected using an injection volume of $5 \mathrm{ml} / \mathrm{kg}$. All ER modulators and their corresponding VEH solutions were administered subcutaneously (s.c.), whereas AMPH and the corresponding SAL control solution were injected intraperitoneally (i.p.). 


\section{Statistical analyses}

In the experimental series testing the effects of MPP, PPT, PHTPP or DPN on basal PPI, \% PPI was analyzed using a $3 \times 3 \times 3$ (treatment $\times$ prepulse level $\times$ pulse level) parametric ANOVA; and reactivities to pulse-alone and prepulse-alone trials were analyzed using a $3 \times 3$ (treatment $\times$ pulse level) and $3 \times 3$ (treatment $\times$ prepulse level) parametric ANOVA, respectively. In experimental series testing the effects of selective ER- $\alpha$ modulators (MPP and PPT) or ER- $\beta$ modulators (DPN or PHTPP) on AMPH-induced PPI deficits, \% PPI was analyzed using a $4 \times 3 \times 3$ (treatment $\times$ prepulse level $\times$ pulse level) parametric ANOVA; and reactivities to pulse-alone and prepulse-alone trials were analyzed using a $4 \times 3$ (treatment $\times$ pulse level) and $4 \times 3$ (treatment $\times$ prepulse level) parametric ANOVA, respectively. These analyses were followed by Fisher's LSD post-hoc comparisons whenever appropriate. Statistical significance was set at $p<0.05$. All statistical analyses were performed using the statistical software StatView (version 5.0) implemented on a PC running the Windows XP operating system.

\section{Results}

\section{Acute ER- $\alpha$ activation by systemic PPT administration enhances PPI}

First, we explored the consequences of acute ER- $\alpha$ activation on sensorimotor gating by assessing the effects of systemic administration of the ER- $\alpha$ selective agonist PPT on PPI in male mice. The analysis of \% PPI revealed a significant overall difference in \% PPI levels across the different pharmacological treatment groups (main effect of treatment: $F_{(2,21)}=$ $3.61, p<0.05)$. Post-hoc analyses revealed that the high dose of PPT $(10 \mathrm{mg} / \mathrm{kg}$, s.c.) led to a significant $(p<0.05)$ increase in PPI, whereas the low dose of PPT $(1 \mathrm{mg} / \mathrm{kg})$ failed to do 
so. As summarized in Fig. 1a, the mean PPI scores were $\sim 20 \%$ higher in mice injected with $10 \mathrm{mg} / \mathrm{kg}$ PPT compared to VEH-treated animals. The interaction between drug and pulse levels, and between drug and prepulse levels, failed to reach statistical significance in the analysis, suggesting that the PPI-ameliorating effects of PPT largely emerged independently of the precise pulse stimuli used (Fig. 1a).

As expected, the reactivity to pulse-alone trials increased with increasing pulse levels (main effect of pulse levels: $F_{(2,42)}=12.46, p<0.001$ ) and this effect was similar in all three treatment groups (Fig. 1b). PPT treatment did also not affect the reactivity to prepulsealone trials (data not shown). Together, these data suggest that the ER- $\alpha$ selective agonist PPT induces a dose-dependent enhancement of basal PPI in the absence of concomitant changes in pulse or prepulse reactivity.

\section{Acute ER- $\alpha$ blockade by systemic MPP administration attenuates PPI}

Next, we explored the effects of acute ER- $\alpha$ blockade on sensorimotor gating in male mice. To this end, we pretreated the animals with two distinct doses (20 and $200 \mu \mathrm{g} / \mathrm{kg}$ ) of the selective ER- $\alpha$ antagonist MPP before the assessment of PPI. As depicted in Fig. 2a, MPP treatment led to a dose-dependent attenuation of \% PPI: Whereas animals injected with VEH and the low dose of MPP displayed highly comparable PPI levels, pretreatment with the high dose of MPP reduced the mean \% PPI scores by $~ 30 \%$. Statistical support for these impressions was obtained by the presence of a significant main effect of treatment $\left(F_{(2,21)}=3.35, p<0.05\right)$, and by the subsequent post-hoc analyses confirming a significant difference between mice injected with the high dose of MPP and VEH-treated mice $(p<$ $0.05)$ or mice treated with the low dose of MPP $(p<0.05)$. The PPI-disrupting effects of 
MPP emerged independently of the precise pulse or prepulse stimuli used, and no significant interaction involving treatment and pulse, or treatment and prepulse, emerged in the analysis of \% PPI.

The analysis of pulse-alone trials confirmed that the overall startle reactivity increased with increasing pulse levels, leading to a significant main effect of pulse $\left(F_{(2,42)}=118.52, p\right.$ $<0.001$ ). This effect did not interact with the pharmacological treatment (Fig. 2b). MPP treatment did also not affect the reactivity to prepulse-alone trials (data not shown). Together, these data indicate that the ER- $\alpha$ selective antagonist MPP dose-dependently attenuates basal PPI in the absence of concomitant changes in pulse or prepulse reactivity.

\section{Acute ER- $\beta$ activation fails to affect basal PPI but reduces startle reactivity}

Given that acute pharmacological ER- $\alpha$ stimulation increased basal sensorimotor gating (see Fig. 1), we were interested in exploring whether similar effects could be obtained by selective ER- $\beta$ activation. Therefore, we assessed PPI following acute systemic treatment with the ER- $\beta$ selective agonist DPN ( 1 or $10 \mathrm{mg} / \mathrm{kg}$ ) or VEH. We found that the mean \% PPI scores were largely comparable between the 3 treatment groups, even though administration of the low dose of DPN $(1 \mathrm{mg} / \mathrm{kg})$ seemed to induce a slight but nonsignificant reduction in \% PPI at the $100 \mathrm{~dB}$-pulse condition (Fig. 3a). No main effects or interactions involving the between-subjects factor of treatment attained statistical significance in the analyses of \% PPI.

On the other hand, DPN treatment led to a dose-dependent decrease in startle reactivity, which was most noticeable at the $120 \mathrm{~dB}$-pulse condition (Fig. 3b). The analysis of pulse-alone reactivity revealed a significant main effect of pulse levels $\left(F_{(2,42)}=80.34, p<\right.$ 
$0.001)$ and its interaction with treatment $\left(F_{(4,42)}=2.66, p<0.05\right)$. Subsequent post-hoc comparisons confirmed that animals treated with the high dose of DPN $(10 \mathrm{mg} / \mathrm{kg})$ displayed a significant reduction in startle reactivity at the $120 \mathrm{~dB}$-pulse condition relative to VEH controls $(p<0.05)$ or to animals treated with the low $(1 \mathrm{mg} / \mathrm{kg})$ dose of DPN $(p<$ 0.05). DPN administration did not affect the reactivity to prepulse-alone trials (data not shown). Together, these data suggest that the ER- $\beta$ selective agonist DPN does not affect basal PPI at effective doses that reduce startle reactivity. This impression was further confirmed by complementary analyses in experimental subgroups (artificially) matched for their startle reactivity levels (an approach documented by Geyer and Swerdlow, 2001) by which extreme responders from each of the experimental groups were excluded. We found that DPN treatment did not affect PPI levels, even when startle levels were equal (Supplementary Fig. 1), thus convincingly allowing to disambiguate the effects of DPN on startle and PPI.

\section{Acute ER- $\beta$ blockade fails to affect basal PPI and startle reactivity}

In keeping with the PPI-disrupting effects of acute ER- $\alpha$ blockade (see Fig. 2), we went on to investigate whether comparable effects might emerge following acute pharmacological inhibition of ER- $\beta$. To this end, we treated mice with the ER- $\beta$ selective antagonist PHTPP (0.4 or $4 \mathrm{mg} / \mathrm{kg}$ ) or VEH prior to the assessment of PPI. At the chosen

doses, however, PHTPP did not affect \% PPI (Fig. 4a), nor did it change startle reactivity to pulse alone trials (Fig. $\mathbf{4 b}$ ) or prepulse-alone reactivity (data not shown). 


\section{AMPH-induced PPI deficits are attenuated by acute treatment with the ER- $\alpha$ selective agonist PPT}

In a next series of experiments, we tested whether treatment with ER- $\alpha$ selective modulators might also be effective in modifying PPI in an acute hyperdopaminergic state that was induced by systemic administration of the indirect dopamine receptor agonist AMPH (4 mg/kg). As expected, AMPH treatment led to a robust $(\sim 30 \%)$ reduction in $\%$ PPI compared to SAL control treatment (Fig. 5a). The PPI-reducing effects of AMPH were similarly seen in animals pretreated with the ER- $\alpha$ selective antagonist MPP $(10 \mathrm{mg} / \mathrm{kg})$, but absent in mice that received the ER- $\alpha$ selective agonist PPT $(200 \mu \mathrm{g} / \mathrm{kg})$ (Fig. 5a). These effects led to a significant main effect of treatment $\left(F_{(3,28)}=5.96, p<0.01\right)$ in the analysis of \% PPI. Subsequent post-hoc comparisons confirmed a significant difference between the SAL/VEH and AMPH/VEH groups $(p<0.01)$, the SAL/VEH and AMPH/MPP groups $(p<0.001)$, the AMPH/PPT and AMPH/VEH groups ( $\mathrm{p}<0.01)$, and the AMPH/MPP and AMPH/PPT groups $(p<0.05)$.

Mice assigned to the AMPH/MPP group tended to exhibit lower levels of startle reactivity to pulse alone-trials (Fig. 5b), but this effect did not reach statistical significance. Similarly, AMPH, neither alone nor in combination with MPP or PPT, affected the reactivity to prepulse-alone trials (data not shown). Together, these data show that AMPH-induced PPI deficits are attenuated by acute treatment with the ER- $\alpha$ selective agonist PPT independently of concomitant effects on pulse or prepulse reactivity. 


\section{AMPH-induced PPI deficits are attenuated by systemic treatment with the ER- $\beta$ selective agonist DPN}

Even though acute pharmacological modulation of ER- $\beta$ by systemic DPN and PHTPP treatment exerted no noticeable effects on PPI under basal conditions (see Fig. 3 and Fig. 4), we went on to test whether these ER- $\beta$ ligands might modify PPI in a hyperdopaminergic state induced by systemic AMPH treatment. In line with our previous findings (Fig. 5a), we found that AMPH administration led to a marked ( $35 \%)$ reduction in \% PPI (Fig. 6a). The PPI-disrupting effects of AMPH similarly emerged in animals pretreated with the ER- $\beta$ selective antagonist PHTPP (4 mg/kg). On the other hand, pretreatment with the ER- $\beta$ selective agonist DPN $(10 \mathrm{mg} / \mathrm{kg})$ mitigated the negative consequences of AMPH on PPI (Fig. 6a). Statistical support for these impressions was obtained by the significant main effect of treatment $\left(F_{(3,28)}=7.14, p<0.01\right)$, and by the subsequent post-hoc comparisons revealing a significant difference between the SAL/VEH and AMPH/VEH groups $(p<0.001)$, the SAL/VEH and AMPH/PHTPP groups $(p<0.01)$, the AMPH/DPN and AMPH/VEH groups $(p<0.05)$, and the AMPH/DPN and AMPH/PHTPP groups $(p<0.05)$.

The reactivities to pulse alone-trials were largely comparable among the 4 groups (Fig. 6b), and no main effect or interaction involving the between-subjects factor of treatment attained statistical significance in the analysis of startle reactivity. Similarly, AMPH, neither alone nor in combination with DPN or PHTPP, affected the reactivity to prepulse-alone trials (data not shown). Together, these data indicate that the AMPH-induced PPI deficits can be blocked by acute pretreatment with the ER- $\beta$ selective agonist DPN in the absence of concomitant effects on pulse or prepulse reactivity. 


\section{Discussion}

The present study is the first demonstration that isoform-specific ER ligands can effectively modulate PPI of the acoustic startle reflex in mice. Specifically, we demonstrate that systemic administration of the ER- $\alpha$ agonist PPT can enhance PPI both under basal and hyperdopaminergic conditions, suggesting that signaling at ER- $\alpha$ has a substantial impact on the modulation of sensorimotor gating. This impression is further supported by our findings showing that pharmacological blockade of ER- $\alpha$ signaling by acute MPP treatment attenuates PPI. It thus appears that endogenous ER- $\alpha$ signaling has a bidirectional role in the regulation of PPI, so that stimulation and attenuation of ER- $\alpha$ signaling is linked to an enhancement and disruption of sensorimotor gating, respectively. Notably, such bidirectional effects are not unique to ER- $\alpha$ signaling but have been described for various other neurotransmitter systems. Perhaps the best illustration in this context is the central dopamine system: It is well known that manipulations leading to enhanced presynaptic dopamine release and/or dopamine receptor stimulation (especially in striatal structures) impair PPI, whereas blockade of dopamine receptor signaling potentiates PPI and/or restores PPI deficits associated with hyperdopaminergic states (Swerdlow et al. 2000). It should also be pointed out that the PPI-modulating effects of ER- $\alpha$ selective ligands likely represent genuine effects on central gating mechanisms. Indeed, they were not associated with concomitant changes in startle or prepulse reactivity, which in turn may complicate the interpretation of gating effects (Csomor et al. 2008; Yee et al. 2005).

Our results further suggest the existence of a more functionally restricted role for ER- $\beta$ signaling in the modulation of PPI. Whereas selective ligands for the ER- $\beta$ receptor did not alter PPI scores under basal conditions, ER- $\beta$ activation efficiently enhanced PPI when the 
animals were shifted towards a hyperdopaminergic condition by acute administration of AMPH. One limitation of the present study is that the effects of ER- $\alpha$ or ER- $\beta$ selective ligands were studied using two doses for each compound only. Hence, we cannot rule out the possibility that treatment with higher doses of ER- $\beta$ selective modulators may still be effective in modulating PPI under basal conditions. Importantly, although the ER- $\beta$ selective antagonist PHTPP was shown to effectively modulate behavioral functions by other laboratories when administered centrally (Dillon et al. 2013; Saleh et al. 2013), it did not exhibit biological activity in any of the experimental investigations described herein (peripheral administration) so that it is not feasible to fully conclude as to the absence of effects of PHTPP on PPI or startle. Indeed, one possible interpretation of our findings is that PHTTP does not affect PPI or startle because of a reduced bioactivity level within brain circuits involved in sensorimotor gating and future studies are thus required to address this possibility.

On the other hand, it needs to be pointed out that treatment with the ER- $\beta$ selective agonist DPN was found to significantly reduce startle reactivity under basal conditions whilst leaving PPI unaffected. This dissociation may be indicative of the possibility that ER$\beta$ signaling, at least under basal conditions, could be functionally more relevant for the regulation of the startle reflex per se as for the modulation of the gating mechanism underlying PPI (Koch and Schnitzler, 1997). Further evidence for this experimental dissociation between startle and PPI arises from complementary analyses in experimental subgroups matched for their startle reactivity levels (as documented by Geyer and Swerdlow, 2001). Using such approach, we readily demonstrate that DPN, under similar (matched) startle conditions, does not affect PPI levels (Supplementary Fig. 1), thus 
suggesting that the effects of DPN on startle are likely not masking any of its possible effects on PPI. Even though this hypothesis warrants further investigations, it would be consistent with the proposal that the startle response and PPI represent two independent and somewhat dissociable processes (Blumenthal et al. 2004; Ison et al. 1997).

Another possible explanation for the ineffectiveness of the ER- $\beta$ selective agonist DPN to enhance PPI under basal conditions may be related to the fact that the second cohort of animals (i.e., those that were used to study ER- $\beta$ selective modulators) generally displayed high PPI scores, even after VEH treatment. Indeed, whereas the mean \% PPI scores in VEHtreated animals from cohort 1 ranged from 50 to 60\%, VEH-treated animals from cohort 2 displayed \% PPI scores between 70 to $80 \%$. Given this, the ineffectiveness of the ER- $\beta$ selective agonist DPN to increase basal PPI may be related to ceiling effects, that is, they could have been masked by high PPI scores in VEH-treated animals. We have no parsimonious explanation for the apparent differences between the baseline PPI scores of cohort 1 and 2. It should be noted, however, that individual differences in baseline PPI are not uncommon, and they do exist even within one particular mouse strain such as C57BL/6 (see e.g., Yee et al. 2005).

Even though the effectiveness of the ER- $\alpha$ and ER- $\beta$ selective agonists differed with respect to the modulation of PPI under basal conditions, they were remarkably similar in their capacity to enhance PPI under hyperdopaminergic conditions. These findings readily emphasize a putative role of dopamine-dependent mechanisms in the behavioral actions of ER- $\alpha$ and ER- $\beta$ selective agonists. In support of this notion, E2 is known to affect dopaminergic neurocircuits (Sánchez et al. 2010), and it has been proposed that such effects readily contribute to the modulatory effects of E2 on sensorimotor gating in the 
form of PPI (Gogos et al. 2010, 2012). Moreover, ER- $\alpha$ and ER- $\beta$ are both expressed in some of the most important brain areas involved in the PPI circuitry, including the (ventral) striatum and midbrain dopaminergic nuclei (Kuppers and Beyer, 1999; Laflamme et al. 1998; Shughrue et al. 1997; Toran-Allerand, 2004). Previous studies have further shown that E2 treatment-can recruit ER- $\alpha$ and ER- $\beta$ to efficiently modulate striatal dopaminergic signaling. For example, acute E2 rapidly modifies dopamine release in the striatum, and these effects were shown to depend on both ER- $\alpha$ and ER- $\beta$ subtypes, supporting the idea that these ERs exhibit functional activity in the striatum (likely) via recruitment of nongenomic mechanisms (Bazzett and Becker, 1994; Xiao et al. 2003). Two-week chronic administration of ER- $\alpha$ and ER- $\beta$ selective ligands, that mostly involve genomic activity of ERs, similarly implicated dopaminergic signaling pathways (Le Saux et al. 2006). Under such conditions, to target both (and perhaps equally important) genomic and non-genomic signaling mechanisms, our series of investigations thus comprised of a treatment regimen whereby ER drugs were administered 1 hour prior to behavioral testing, in a test that lasted 45 min (Lösel and Wehling, 2003).

A number of distinct (but not mutually exclusive) processes have been proposed whereby ER signaling can modulate dopaminergic activity. One prevailing hypothesis suggests that activation of ERs located on presynaptic DA terminals or post-synaptic dopaminoceptive neurons could modulate dopamine release (Madularu et al. 2014), dopamine transporter (DAT) and D2 receptors (D2R) activity and affinity (Bazzett and Becker, 1994; Cyr et al. 2002; Lévesque and Di Paolo, 1988; Morissette et al. 1990). Such effects have been repeatedly shown to emerge in the absence of gene expression changes (Di Paolo, 1994). For example, an elegant study by Chavez and colleagues revealed that an 
E2 administration regimen known to enhance PPI (Gogos et al. 2006) leads to reductions in dopamine D2 receptor density in the nucleus accumbens of OVX rats, and causes an increase in DAT density (Chavez et al. 2010). Whether similar mechanisms may also be operative following administration of ER- $\alpha$ and ER- $\beta$ selective agonists, and whether these may explain the PPI-improving effects of these compounds under hyperdopaminergic conditions, warrants further investigation.

Although the involvement of dopaminergic mechanisms appears compelling, various other neurochemical mechanisms may also be involved in the PPI-modifying effects of ER ligands. Indeed, E2 was previously shown to blunt the deleterious effects of the NMDA antagonist MK-801 on PPI (Gogos et al. 2012; Van den Buuse and Eikelis, 2001) and on selective attention learning (Arad and Weiner, 2010b). Several studies have further implicated 5-HT1 and 5-HT2A serotonergic receptors in the behavioral effects of E2 and related ligands (Cyr et al. 2002; Fink et al. 1998; Gogos et al. 2012; Weiner and Arad, 2009). These mechanisms may be particularly important in mediating the effects of the ER- $\alpha$ selective agonist PPT on PPI given that this drug was shown to enhance PPI levels both under basal and hyperdopaminergic conditions. Indeed, one limitation of our study is that we did not include a SAL/PPT group in the AMPH experimental investigations so that it is not feasible to conclude whether PPT functionally rescues the AMPH-effects on PPI, or rather whether PPT enhances PPI in an additive fashion via other (unrelated) mechanisms. Additional studies are thus clearly warranted to further delineate the precise neurochemical processes underlying the PPI-modifying effects of ER isoform-specific ligands. 
Whatever precise mechanisms involved, our findings clearly add to the growing literature suggesting that estrogen-related substances may have therapeutic value in the treatment of psychosis-related behavioral and cognitive deficits (Arad and Weiner, 2010b; Frye et al. 2007; Gogos et al. 2006, 2010, 2012; Uban et al. 2012; Van den Buuse and Eikelis, 2001). For instance the ER- $\alpha$ agonist PPT seems to represent a remarkably potent pharmacological compound that could possibly modulate PPI in populations of patients with sensorimotor gating pathologies of distinct etiology/pathophysiology given its significant effects on PPI both in normo-dopaminergic and hyper-dopaminergic states. Notably, since our study was conducted in male mice, our findings support the idea that such estrogen-based interventions may not only be beneficial for female subjects suffering from psychosis-related disturbances, but could be readily extended to the pharmacological treatment of the male schizophrenic population. Thus far, only a small number of pilot studies have investigated potential benefits of estrogen as an adjunctive therapy for men with schizophrenia (Kulkarni et al. 2009, 2011, 2013). Unfortunately, the risk of inducing hormone-dependent cancers, and the possibility that such therapy may have feminizing effects in the male population, has limited the applicability of an adjunctive estrogen therapy in male schizophrenic patients (Cyr et al. 2002; Kulkarni et al. 2009). The use of ER selective ligands may be less prone to such side effects as they would allow reducing administration doses, thus limiting the emergence of estrogen-related peripheral sideeffects. An interesting candidate for these purposes would be the ER- $\beta$ agonist DPN because it enhanced PPI levels under hyperdopaminergic conditions and is known to mostly spare peripheral functions (Bliedtner et al. 2010; Le Saux et al. 2006;). Against these backgrounds, our study may thus encourage additional investigations aiming at 
establishing novel ER-based therapeutic interventions in schizophrenia and related disorders.

In conclusion, our study demonstrates for the first time that sensorimotor gating as assessed by the PPI paradigm is highly sensitive to manipulations targeting the ER- $\alpha$ and, to a more restricted extent, the ER- $\beta$ receptor subtype. Whereas ER- $\alpha$ selective ligands appear more potent in modulating PPI under basal conditions, activation of either subtype exerts PPI-improving effects under acute hyperdopaminergic conditions. ER isoformselective compounds may represent a novel therapeutic opportunity for the treatment of psychosis-related abnormalities, with potentially lesser side-effects on the peripheral machinery compared to the more conventional E2 treatment approaches. 


\section{References}

Angermeyer MC, Kühn L (1988) Gender differences in age at onset of schizophrenia. An overview. Eur Arch Psychiatry Neurol Sci 237:351-64.

Arad M, Weiner I (2010a) Contrasting effects of increased and decreased dopamine transmission on latent inhibition in ovariectomized rats and their modulation by 17beta-estradiol: an animal model of menopausal psychosis? Neuropsychopharmacology 35:1570-82.

Arad M, Weiner I (2010b) Sex-dependent antipsychotic capacity of $17 \beta$-estradiol in the latent inhibition model: a typical antipsychotic drug in both sexes, atypical antipsychotic drug in males. Neuropsychopharmacology 35:2179-92.

Bazzett TJ, Becker JB (1994) Sex differences in the rapid and acute effects of estrogen on striatal D2 dopamine receptor binding. Brain Res 637:163-72.

Becker JB, Rudick CN (1999) Rapid effects of estrogen or progesterone on the amphetamine-induced increase in striatal dopamine are enhanced by estrogen priming: a microdialysis study. Pharmacol Biochem Behav 64:53-7.

Bliedtner A, Ziera O, Albrecht S, Liebhaber S, Vollmer G (2010) Effects of genistein and estrogen receptor subtype-specific agonists in ArKO mice following different administration routes. Mol Cell Endocrinol 314:41-52.

Blumenthal TD, Elden A, Flaten MA (2004) A comparison of several methods used to quantify prepulse inhibition of eyeblink responding. Psychophysiology 41:326-332.

Bowers BJ, McClure-Begley TD, Keller JJ, Paylor R, Collins AC, Wehner JM (2005) Deletion of the alpha7 nicotinic receptor subunit gene results in increased sensitivity to several behavioral effects produced by alcohol. Alcohol Clin Exp Res 29:295-302. 
Braff DL, Geyer MA, Light GA, Sprock J, Perry W, Cadenhead K, Swerdlow NR (2001) Impact of prepulse characteristics on the detection of sensorimotor gating deficits in schizophrenia. Schizophr Res 49:171-178.

Chavez C, Hollaus M, Scarr E, Pavey G, Gogos A, van den Buuse M (2010) The effect of estrogen on dopamine and serotonin receptor and transporter levels in the brain: an autoradiography study. Brain Res 1321:51-9.

Compton DR, Sheng S, Carlson KE, Rebaczk NA, Lee IY, Katzenellenbogen BS, Katzenellenbogen JA (2004) Pyrazolo[1,5-a]pyrimidines: estrogen receptor ligands possessing estrogen receptor beta antagonist activity. J Med Chem 47:5872-5893.

Csomor PA, Yee BK, Vollenweider FX, Feldon J, Nicolet T, Quednow BB (2008) On the influence of baseline startle reactivity on the indexation of prepulse inhibition. Behav Neurosci 122:885-900.

Cyr M, Calon F, Morissette M, Di Paolo T (2002) Estrogenic modulation of brain activity: implications for schizophrenia and Parkinson's disease. J Psychiatry Neurosci 27:1227.

Di Paolo T (1994) Modulation of brain dopamine transmission by sex steroids. Rev Neurosci 5:27-41.

Dillon TS, Fox LC, Han C, Linster C (2013) 17ß-estradiol enhances memory duration in the main olfactory bulb in CD-1 mice. Behav Neurosci 127:923-31.

Fink G, Sumner BE, McQueen JK, Wilson H, Rosie R (1998) Sex steroid control of mood, mental state and memory. Clin Exp Pharmacol Physiol 25:764-75. 
Flood DG, Zuvich E, Marino MJ, Gasior M (2010). The effects of d-amphetamine, methylphenidate, sydnocarb, and caffeine on prepulse inhibition of the startle reflex in DBA/2 mice. Psychopharmacology 211:325-336.

Frasor J, Barnett DH, Danes JM, Hess R, Parlow AF, Katzenellenbogen BS (2003) Responsespecific and ligand dose-dependent modulation of estrogen receptor (ER) alpha activity by ERbeta in the uterus. Endocrinology 144:3159-66.

Frye CA, Duffy CK, Walf AA (2007) Estrogens and progestins enhance spatial learning of intact and ovariectomized rats in the object placement task. Neurobiol Learn Mem. 88:208-16.

Geyer MA, Swerdlow NR (2001) Measurement of startle response, prepulse inhibition, and habituation. Curr Protoc Neurosci Chapter 8:Unit 8.7.

Gogos A, Kwek P, Chavez C, van den Buuse M (2010) Estrogen treatment blocks 8-hydroxy2-dipropylaminotetralin- and apomorphine-induced disruptions of prepulse inhibition: involvement of dopamine D1 or D2 or serotonin 5-HT1A, 5-HT2A, or 5HT7 receptors. J Pharmacol Exp Ther 333:218-227

Gogos A, Kwek P, van den Buuse M (2012) The role of estrogen and testosterone in female rats in behavioral models of relevance to schizophrenia. Psychopharmacology (Berl) 219:213-224

Gogos A, Nathan PJ, Guille V, Croft RJ, van den Buuse M (2006) Estrogen prevents 5-HT1A receptor-induced disruptions of prepulse inhibition in healthy women. Neuropsychopharmacology 31:885-9. 
Gogos A, Van den Buuse M (2004) Estrogen and progesterone prevent disruption of prepulse inhibition by the serotonin-1A receptor agonist 8-hydroxy-2dipropylaminotetralin. J Pharmacol Exp Ther 309:267-74.

Graham FK (1975) The more or less startling effects of weak prestimulation. Psychophysiology 12:238-248.

Grassi D, Lagunas N, Amorim M, Pinos H, Panzica G, Garcia-Segura LM, Collado P. Role of oestrogen receptors on the modulation of NADPH-diaphorase-positive cell number in supraoptic and paraventricular nuclei of ovariectomised female rats. J Neuroendocrinol 25:244-50.

Häfner H (2003) Gender differences in schizophrenia. Psychoneuroendocrinology 28:17-54. Harrington WR, Sheng S, Barnett DH, Petz LN, Katzenellenbogen JA, Katzenellenbogen BS (2003) Activities of estrogen receptor alpha- and beta selective ligands at diverse estrogen responsive gene sites mediating transactivation or transrepression. Mol Cell Endocrinol 206:13-22.

Harris HA, Katzenellenbogen JA, Katzenellenbogen BS (2002) Characterization of the biological roles of the estrogen receptors, ERalpha and ERbeta, in estrogen target tissues in vivo through the use of an ERalpha-selective ligand. Endocrinology 143:4172-7.

Heldring N, Pike A, Andersson S, Matthews J, Cheng G, Hartman J, Tujague M, Ström A, Treuter E, Warner M, Gustafsson JA (2007) Estrogen receptors: how do they signal and what are their targets. Physiol Rev 87:905-31.

Hoffman HS, Searle J (1965) Acoustic variables in the modification of the startle reaction in the rat. J Comp Physiol Psychol 60:5-58. 
Huber TJ, Rollnik J, Wilhelms J, von zur Mühlen A, Emrich HM, Schneider U (2001) Estradiol levels in psychotic disorders. Psychoneuroendocrinology 26:27-35.

Huber TJ, Tettenborn C, Leifke E, Emrich HM (2005) Sex hormones in psychotic men. Psychoneuroendocrinology 30:111-4.

Ison JR, Bowen GP, Pak J, Gutierrez E (1997) Changes in the strength of prepulse inhibition with variation in the startle baseline associated with individual differences and with old age in rat and mice. Psychobiology 25:266-274.

Koch M, Schnitzler HU (1997) The acoustic startle response in rats--circuits mediating evocation, inhibition and potentiation. Behav Brain Res 89:35-49.

Kraichely DM, Sun J, Katzenellenbogen JA, Katzenellenbogen BS (2000) Conformational changes and coactivator recruitment by novel ligands for estrogen receptor-alpha and estrogen receptor-beta: correlations with biological character and distinct differences among SRC coactivator family members. Endocrinology 141:3534-45.

Kulkarni J (2009) Oestrogen--a new treatment approach for schizophrenia? Med J Aust 190:S37-8.

Kulkarni J, de Castella A, Headey B, Marston N, Sinclair K, Lee S, Gurvich C, Fitzgerald PB, Burger H (2011) Estrogens and men with schizophrenia: is there a case for adjunctive therapy? Schizophr Res 125:278-83.

Kulkarni J, Gavrilidis E, Worsley R, Van Rheenen T, Hayes E (2013) The role of estrogen in the treatment of men with schizophrenia. Int J Endocrinol Metab 11:129-36.

Kuppers E, Beyer C (1999) Expression of estrogen receptor-alpha and beta mRNA in the developing and adult mouse striatum. Neurosci Lett 276:95-98 
Labouesse MA, Stadlbauer U, Langhans W, Meyer U (2013) Chronic high fat diet consumption impairs sensorimotor gating in mice. Psychoneuroendocrinology. 38:2562-74.

Laflamme N, Nappi RE, Drolet G, Labrie C, Rivest S (1998) Expression and neuropeptidergic characterization of estrogen receptors (ERalpha and ERbeta) throughout the rat brain: anatomical evidence of distinct roles of each subtype. J Neurobiol 36:357-378.

Le Saux M, Di Paolo T (2006) Influence of oestrogenic compounds on monoamine transporters in rat striatum. J Neuroendocrinol 18:25-32.

Le Saux M, Morissette M, Di Paolo T (2006) ERbeta mediates the estradiol increase of D2 receptors in rat striatum and nucleus accumbens. Neuropharmacology 50:451-457

Lévesque D, Di Paolo T (1988) Rapid conversion of high into low striatal D2-dopamine receptor agonist binding states after an acute physiological dose of 17 beta-estradiol. Neurosci Lett 88:113-8.

Lewis MC, Gould TJ (2003) Nicotine and ethanol enhancements of acoustic startle reflex are mediated in part by dopamine in C57BL/6J mice. Pharmacol Biochem Behav 76:17986.

Light GA, Braff DL (1999) Human and animal studies of schizophrenia related gating deficits. Curr Psychiatr Rep 1:31-40

Lösel R, Wehling M (2003) Nongenomic actions of steroid hormones. Nat Rev Mol Cell Biol 4:46-56.

Lund TD, Rovis T, Chun WC, Handa RJ (2005) Novel actions of estrogen receptor-beta on anxiety-related behaviors. Endocrinology 146:797-807. 
Lundholm L, Bryzgalova G, Gao H, Portwood N, Fält S, Berndt KD, Dicker A, Galuska D, Zierath JR, Gustafsson JA, Efendic S, Dahlman-Wright K, Khan A. The estrogen receptor \{alpha\}-selective agonist propyl pyrazole triol improves glucose tolerance in ob/ob mice; potential molecular mechanisms. J Endocrinol 199:275-86.

Lynch JF 3rd, Dejanovic D, Winiecki P, Mulvany J, Ortiz S, Riccio DC, Jasnow AM (2014) Activation of ER $\beta$ modulates fear generalization through an effect on memory retrieval. Horm Behav 66:421-9.

Madularu D, Shams WM, Brake WG (2014) Estrogen potentiates the behavioral and nucleus accumbens dopamine response to continuous haloperidol treatment in female rats. Eur J Neurosci 39:257-65.

Mazzucco CA, Walker HA, Pawluski JL, Lieblich SE, Galea LA (2008) ERalpha, but not ERbeta, mediates the expression of sexual behavior in the female rat. Behav Brain Res 191:111-7.

Meyer U, Feldon J, Schedlowski M, Yee BK (2005) Towards an immuno-precipitated neurodevelopmental animal model of schizophrenia. Neurosci Biobehav Rev 29:913947.

Meyers MJ, Sun J, Carlson KE, Marriner GA, Katzenellenbogen BS, Katzenellenbogen JA (2001) Estrogen receptor-beta potency-selective ligands: structure-activity relationship studies of diarylpropionitriles and their acetylene and polar analogues. J Med Chem 44:4230-4251.

Morissette M, Biron D, Di Paolo T (1990) Effect of estradiol and progesterone on rat striatal dopamine uptake sites. Brain Res Bull 25:419-22. 
Oades RD, Schepker R (1994) Serum gonadal steroid hormones in young schizophrenic patients. Psychoneuroendocrinology 19:373-385.

Owens JC, Balogh SA, McClure-Begley TD, Butt CM, Labarca C, Lester HA, Picciotto MR, Wehner JM, Collins AC (2003) Alpha 4 beta 2* nicotinic acetylcholine receptors modulate the effects of ethanol and nicotine on the acoustic startle response. Alcohol Clin Exp Res 27:1867-75.

Sánchez MG, Bourque M, Morissette M, Di Paolo T (2010) Steroids-dopamine interactions in the pathophysiology and treatment of CNS disorders. CNS Neurosci Ther 16:43-71.

Santollo J, Eckel LA (2009) Effect of a putative ERalpha antagonist, MPP, on food intake in cycling and ovariectomized rats. Physiol Behav 97:193-198.

Santollo J, Katzenellenbogen BS, Katzenellenbogen JA, Eckel LA (2010) Activation of ER $\alpha$ is necessary for estradiol's anorexigenic effect in female rats. Horm Behav 58:872-7.

Santollo J, Wiley MD, Eckel LA (2007) Acute activation of ER alpha decreases food intake, meal size, and body weight in ovariectomized rats. Am J Physiol Regul Integr Comp Physiol 293:2194-2201.

Saleh MC, Connell BJ, Saleh TM (2013) Resveratrol induced neuroprotection is mediated via both estrogen receptor subtypes, ER( $\alpha$ ) and ER( $\beta$ ). Neurosci Lett 548:217-21.

Seeman MV (1997) Psychopathology in women and men: focus on female hormones. Am J Psychiatry 154:1641-7.

Shughrue PJ, Lane MV, Merchenthaler I (1997) Comparative distribution of estrogen receptor-alpha and -beta mRNA in the rat central nervous system. J Comp Neurol 388:507-525. 
Stauffer SR, Coletta CJ, Tedesco R, Nishiguchi G, Carlson K, Sun J, Katzenellenbogen BS, Katzenellenbogen JA (2000) Pyrazole ligands: structure-affinity/activity relationships and estrogen receptor-alpha-selective agonists. J Med Chem 43:4934-4947.

Sun J, Huang YR, Harrington WR, Sheng S, Katzenellenbogen JA, Katzenellenbogen BS (2002) Antagonists selective for estrogen receptor alpha. Endocrinology 143:941-7.

Sun J, Baudry J, Katzenellenbogen JA, Katzenellenbogen BS (2003) Molecular basis for the subtype discrimination of the estrogen receptor-beta-selective ligand, diarylpropionitrile. Mol Endocrinol 17:247-58.

Swerdlow NR, Braff DL, Geyer MA (2000) Animal models of deficient sensorimotor gating: what we know, what we think we know, and what we hope to know soon. Behav Pharmacol 11:185-204.

Tandon R, Nasrallah HA, Keshavan MS (2009). Schizophrenia, "just the facts" 4. Clinical features and conceptualization. Schizophr Res 110:1-23.

Toran-Allerand CD (2004) Minireview: A plethora of estrogen receptors in the brain: where will it end? Endocrinology 145:1069-74.

Uban KA, Rummel J, Floresco SB, Galea LA (2012) Estradiol modulates effort-based decision making in female rats. Neuropsychopharmacology 37:390-401.

Van den Buuse M, Eikelis N (2001) Estrogen increases prepulse inhibition of acoustic startle in rats. Eur J Pharmacol 425:33-41.

Van den Buuse M, Simpson ER, Jones ME (2003) Prepulse inhibition of acoustic startle in aromatase knock-out mice: effects of age and gender. Genes Brain Behav 2:93-102.

Vuillermot S, Weber L, Feldon J, Meyer U (2010) A longitudinal examination of the neurodevelopmental impact of prenatal immune activation in mice reveals primary 
defects in dopaminergic development relevant to schizophrenia. J Neurosci 30:127087.

Waters EM, Yildirim M, Janssen WG, Lou WY, McEwen BS, Morrison JH, Milner TA (2011) Estrogen and aging affect the synaptic distribution of estrogen receptor $\beta$ immunoreactivity in the CA1 region of female rat hippocampus. Brain Res 1379:86-97.

Weiner I, Arad M (2009) Using the pharmacology of latent inhibition to model domains of pathology in schizophrenia and their treatment. Behav Brain Res 204:369-86.

Xiao L, Jackson LR, Becker JB (2003) The effect of estradiol in the striatum is blocked by ICI 182,780 but not tamoxifen: pharmacological and behavioral evidence. Neuroendocrinology 77:239-245.

Yee BK, Chang T, Pietropaolo S, Feldon J (2005) The expression of prepulse inhibition of the acoustic startle reflex as a function of three pulse stimulus intensities, three prepulse stimulus intensities, and three levels of startle responsiveness in C57BL6/J mice. Behav Brain Res 163:265-276. 


\section{Figures}

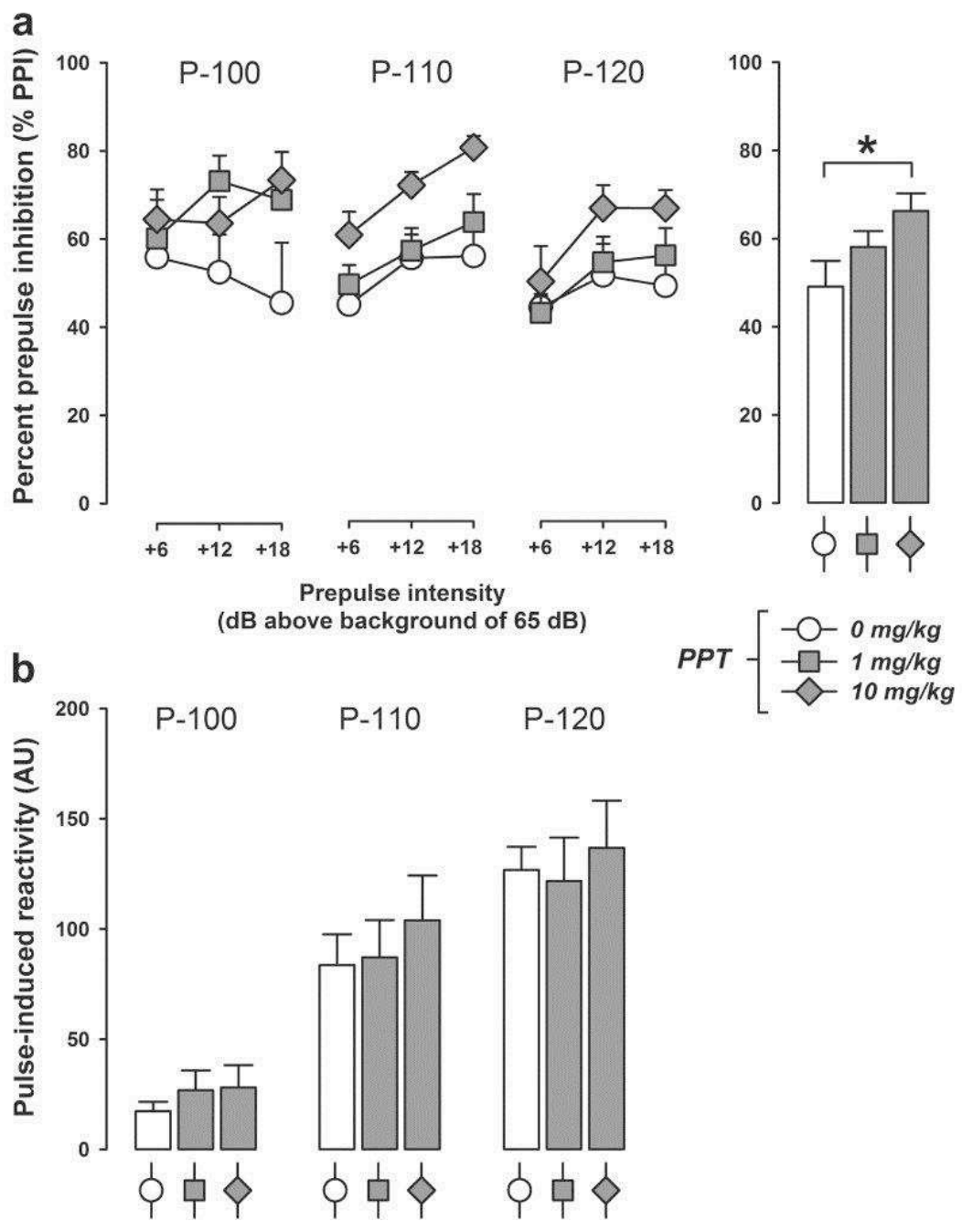

Figure 1. Effect of the ER- $\alpha$ selective agonist PPT on PPI. Mice were injected with vehicle (VEH; $=0 \mathrm{mg} / \mathrm{kg})$ or PPT at a low dose $(1 \mathrm{mg} / \mathrm{kg}$ body weight) or high dose $(10 \mathrm{mg} / \mathrm{kg}$ body weight) $60 \mathrm{~min}$ before PPI testing. (a) The line plot shows percent prepulse inhibition (\% PPI) as a function of the three distinct pulse levels (P-100, P-110, and P-120, which correspond to 100,110 and $\left.120 \mathrm{~dB}_{\mathrm{A}}\right)$ and prepulse levels $\left(+6,+12\right.$ and $+18 \mathrm{~dB}_{\mathrm{A}}$ above background of $65 \mathrm{~dB}_{\mathrm{A}}$ ); and the bar plot depicts the mean \% PPI across all prepulse and pulse stimuli used. ${ }^{*} p<0.05$, based on post-hoc comparisons. (b) The graph shows startle reactivity (in arbitrary units, $\mathrm{AU}$ ) to pulse-alone trials for the three different pulse levels. $N$ $=8$ per group; all values are means + SEM. 


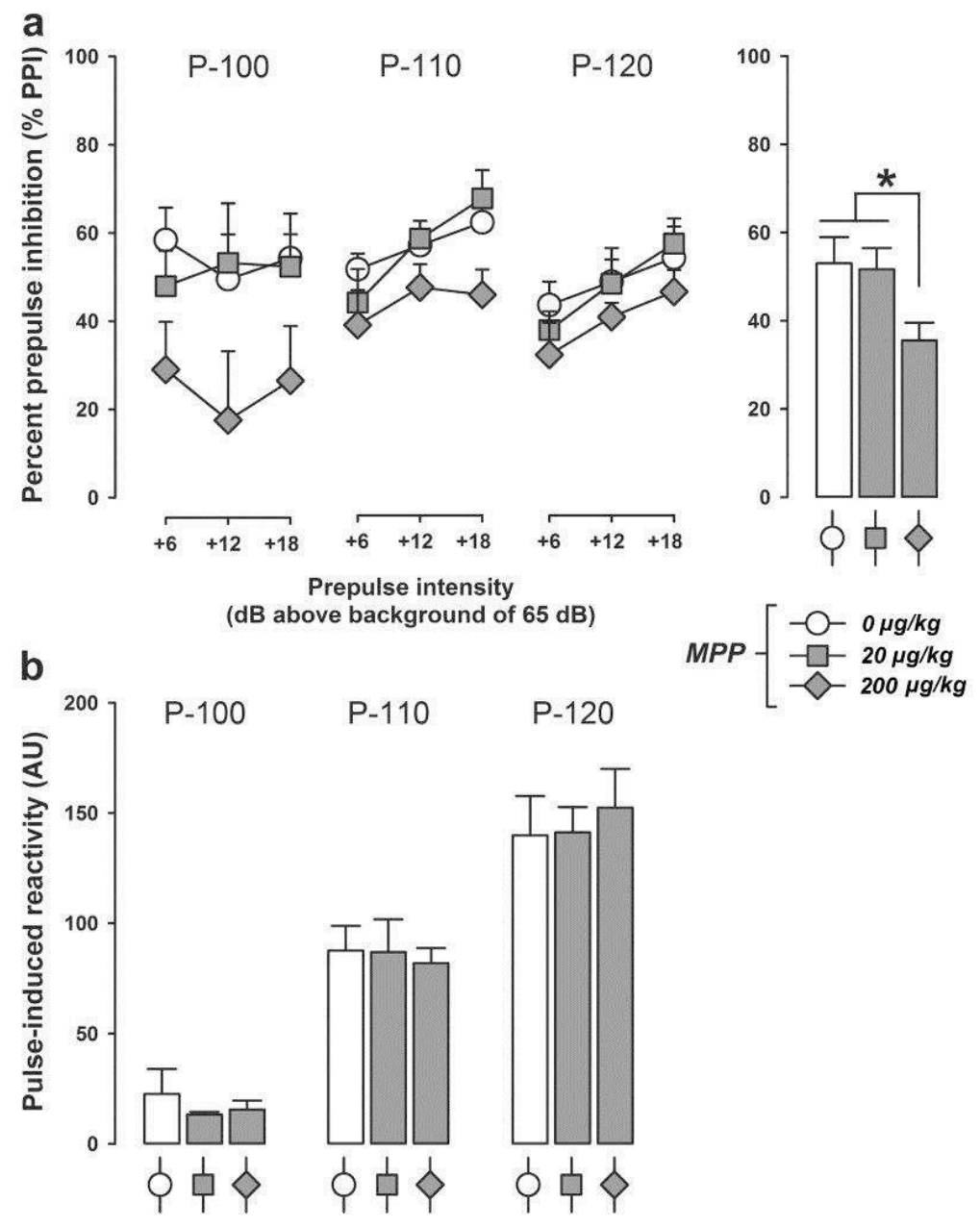

Figure 2. Effect of the ER- $\alpha$ selective antagonist MPP on PPI. Mice were injected with vehicle (VEH; $=0 \mathrm{mg} / \mathrm{kg}$ ) or MPP at a low dose $(20 \mu \mathrm{g} / \mathrm{kg}$ body weight) or high dose (200 $\mu \mathrm{g} / \mathrm{kg}$ body weight) $60 \mathrm{~min}$ before PPI testing. (a) The line plot shows percent prepulse inhibition (\% PPI) as a function of the three distinct pulse levels (P-100, P-110, and P-120, which correspond to 100,110 and $\left.120 \mathrm{~dB}_{\mathrm{A}}\right)$ and prepulse levels $\left(+6,+12\right.$ and $+18 \mathrm{~dB}_{\mathrm{A}}$ above background of $65 \mathrm{~dB}_{\mathrm{A}}$ ); and the bar plot depicts the mean \% PPI across all prepulse and pulse stimuli used. ${ }^{*} p<0.05$, based on post-hoc comparisons. (b) The graph shows startle reactivity (in arbitrary units, $\mathrm{AU}$ ) to pulse-alone trials for the three different pulse levels. $N=8$ per group; all values are means+SEM. 


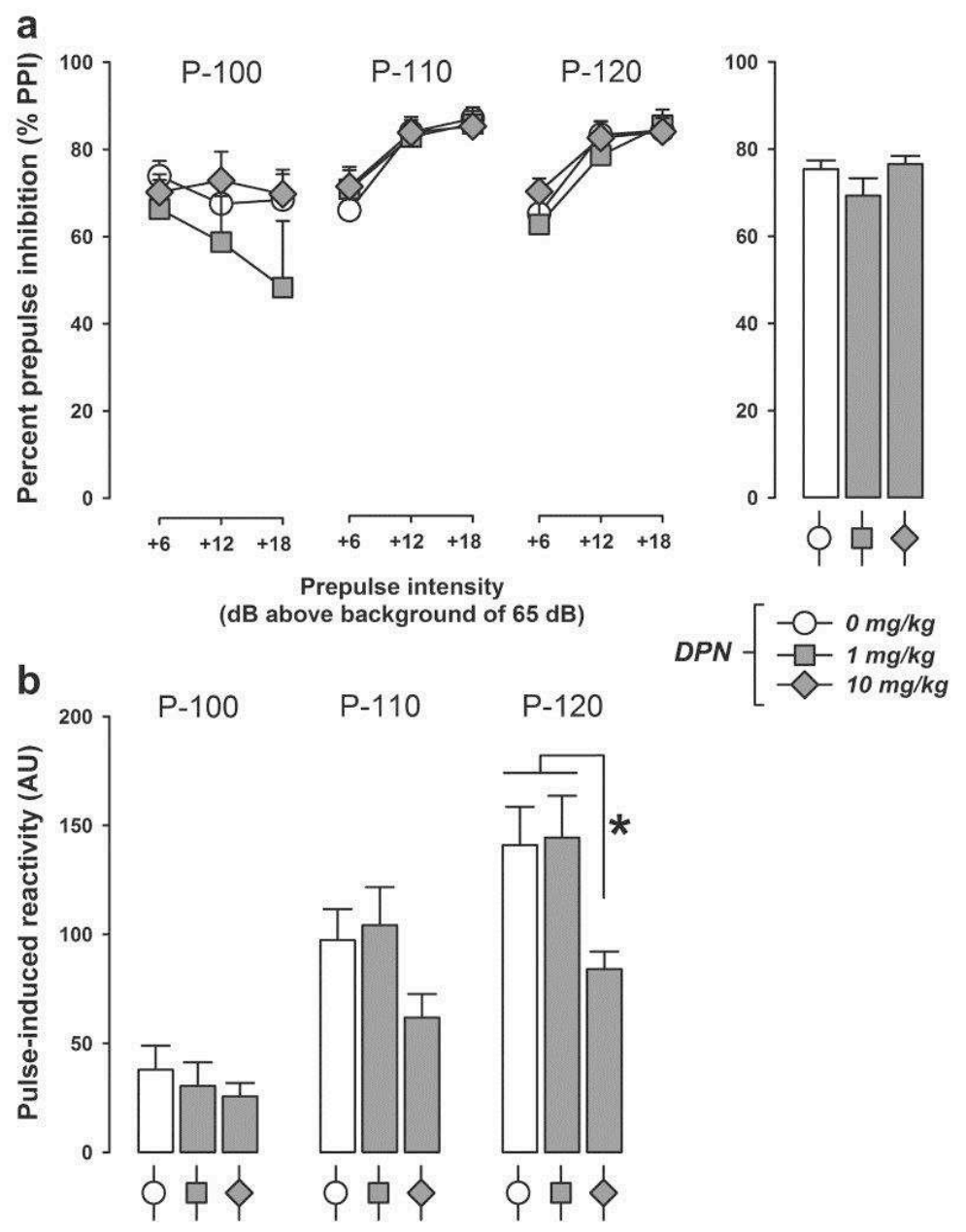

Figure 3. Effects of the ER- $\beta$ selective agonist DPN on PPI. Mice were injected with vehicle (VEH; $=0 \mathrm{mg} / \mathrm{kg})$ or DPN at a low dose $(1 \mathrm{mg} / \mathrm{kg}$ body weight $)$ or high dose $(10 \mathrm{mg} / \mathrm{kg}$ body weight) $60 \mathrm{~min}$ before PPI testing. (a) The line plot shows percent prepulse inhibition (\% PPI) as a function of the three distinct pulse levels (P-100, P-110, and P-120, which correspond to 100,110 and $\left.120 \mathrm{~dB}_{\mathrm{A}}\right)$ and prepulse levels $\left(+6,+12\right.$ and $+18 \mathrm{~dB}_{\mathrm{A}}$ above background of $65 \mathrm{~dB}_{\mathrm{A}}$ ); and the bar plot depicts the mean \% PPI across all prepulse and pulse stimuli used. (b) The graph shows startle reactivity (in arbitrary units, AU) to pulsealone trials for the three different pulse levels. ${ }^{*} p<0.05$, based on post-hoc comparisons conducted for each pulse condition. $N=8$ per group; all values are means \pm SEM. 

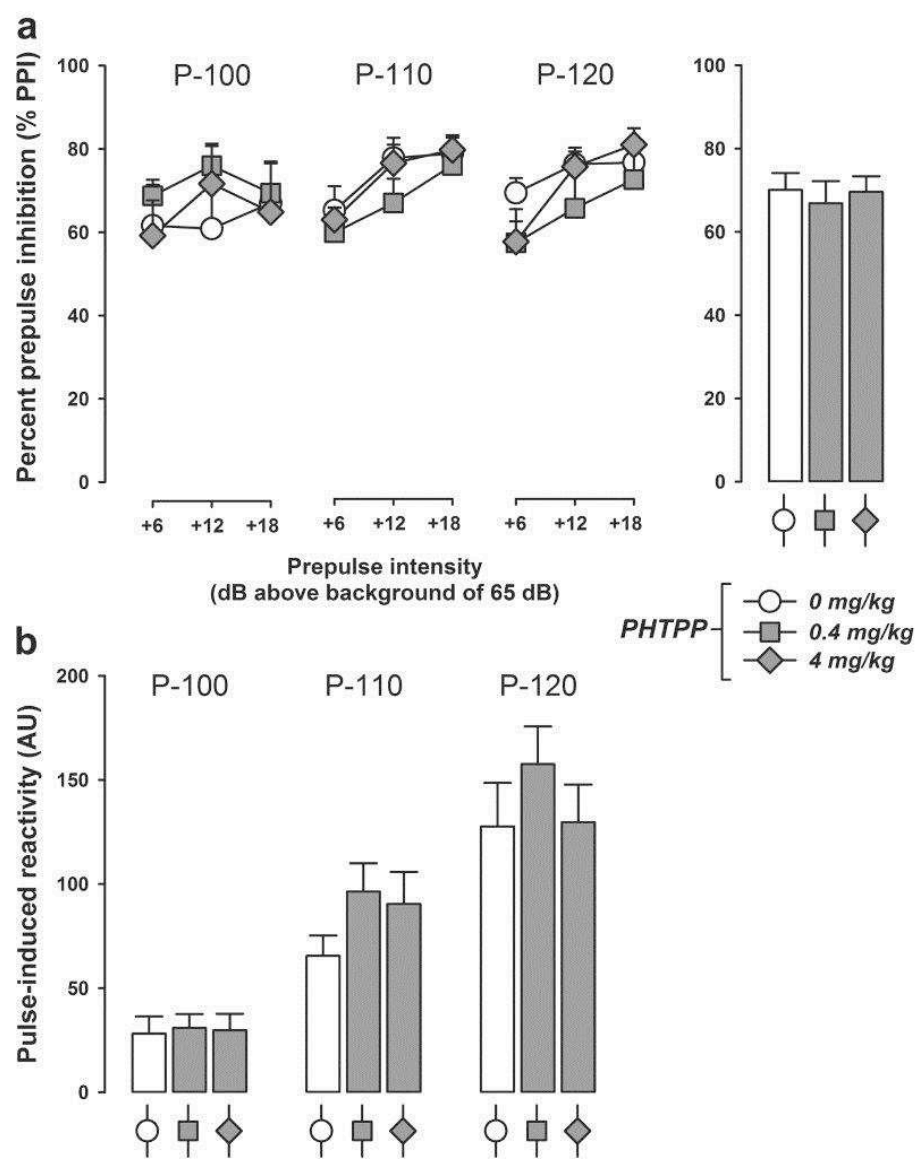

Figure 4. Effects of the ER- $\beta$ selective antagonist PHTPP on PPI. Mice were injected with vehicle (VEH; $=0 \mathrm{mg} / \mathrm{kg}$ ) or PHTPP at a low dose $(0.4 \mathrm{mg} / \mathrm{kg}$ body weight) or high dose (4 $\mathrm{mg} / \mathrm{kg}$ body weight) $60 \mathrm{~min}$ before PPI testing. (a) The line plot shows percent prepulse inhibition (\% PPI) as a function of the three distinct pulse levels (P-100, P-110, and P-120, which correspond to 100,110 and $120 \mathrm{~dB}_{\mathrm{A}}$ ) and prepulse levels $\left(+6,+12\right.$ and $+18 \mathrm{~dB}_{\mathrm{A}}$ above background of $65 \mathrm{~dB}_{\mathrm{A}}$ ); and the bar plot depicts the mean \% PPI across all prepulse and pulse stimuli used. (b) The graph shows startle reactivity (in arbitrary units, AU) to pulse-alone trials for the three different pulse levels. $N=8$ per group; all values are means \pm SEM. 


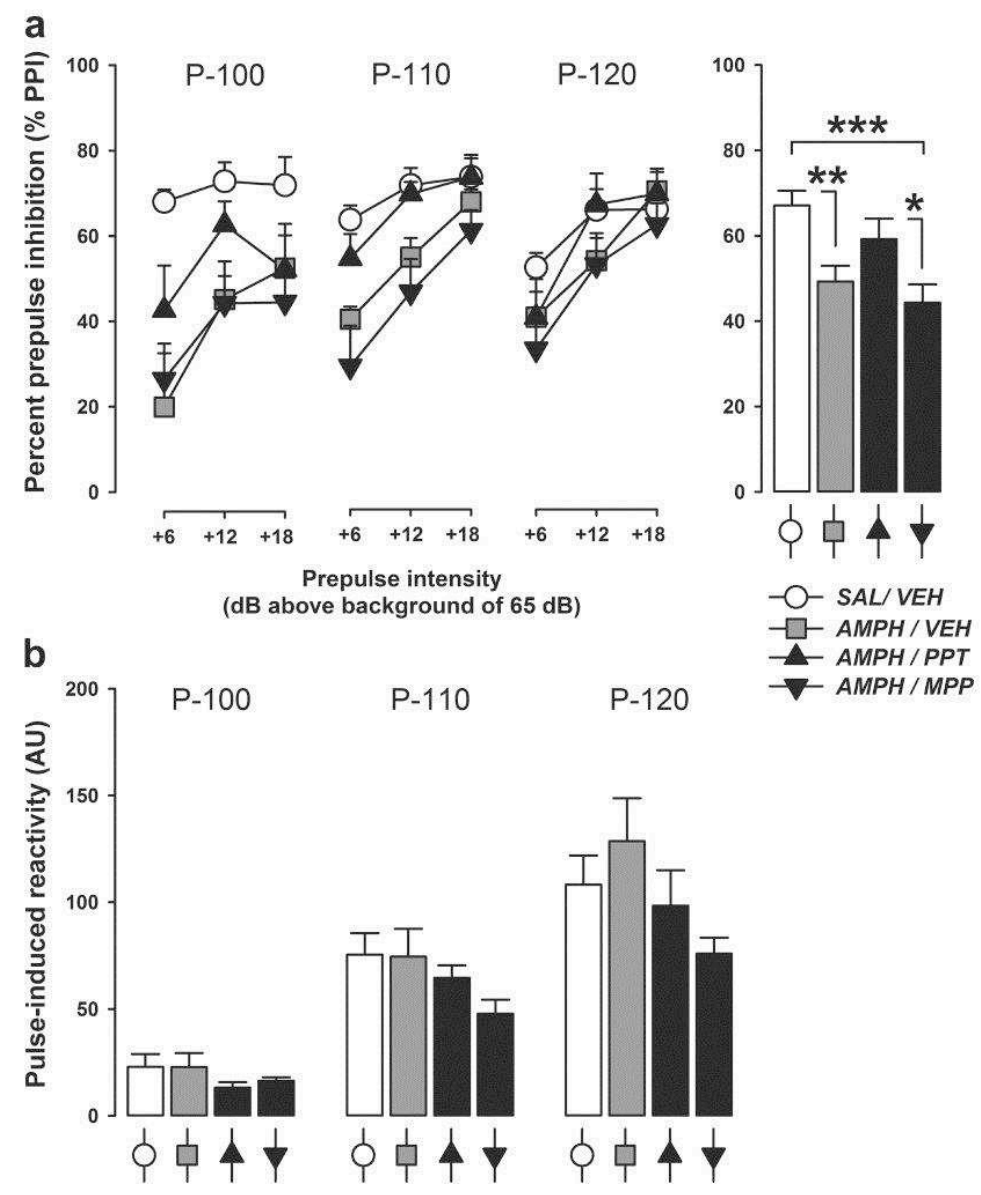

Figure 5. Effects of the ER- $\alpha$ agonist PPT and antagonist MPP on amphetamine-induced PPI deficits. Mice were injected with vehicle (VEH), PPT (10 mg/kg body weight), MPP (200 $\mu \mathrm{g} / \mathrm{kg}$ body weight) $60 \mathrm{~min}$ prior to PPI testing, followed by acute administration of saline (SAL) or amphetamine (AMPH, $4 \mathrm{mg} / \mathrm{kg}$ body weight) 50 min later, yielding 4 treatments groups: SAL/VEH, AMPH/VEH, AMPH/PPT, AMPH/MPP. (a) The line plot shows percent prepulse inhibition (\% PPI) as a function of the three distinct pulse levels (P-100, P-110, and $\mathrm{P}-120$, which correspond to 100,110 and $\left.120 \mathrm{~dB}_{\mathrm{A}}\right)$ and prepulse levels $(+6,+12$ and $+18 \mathrm{~dB}_{\mathrm{A}}$ above background of $65 \mathrm{~dB}_{\mathrm{A}}$ ); and the bar plot depicts the mean \% PPI across all prepulse and pulse stimuli used. ${ }^{*} p<0.05,{ }^{* *} p<0.01$ and ${ }^{* * *} p<0.001$, based on post-hoc comparisons (b) The line plot shows startle reactivity (in arbitrary units, AU) to pulsealone trials for the three different pulse levels. $N=8$ per group; all values are means \pm SEM. 


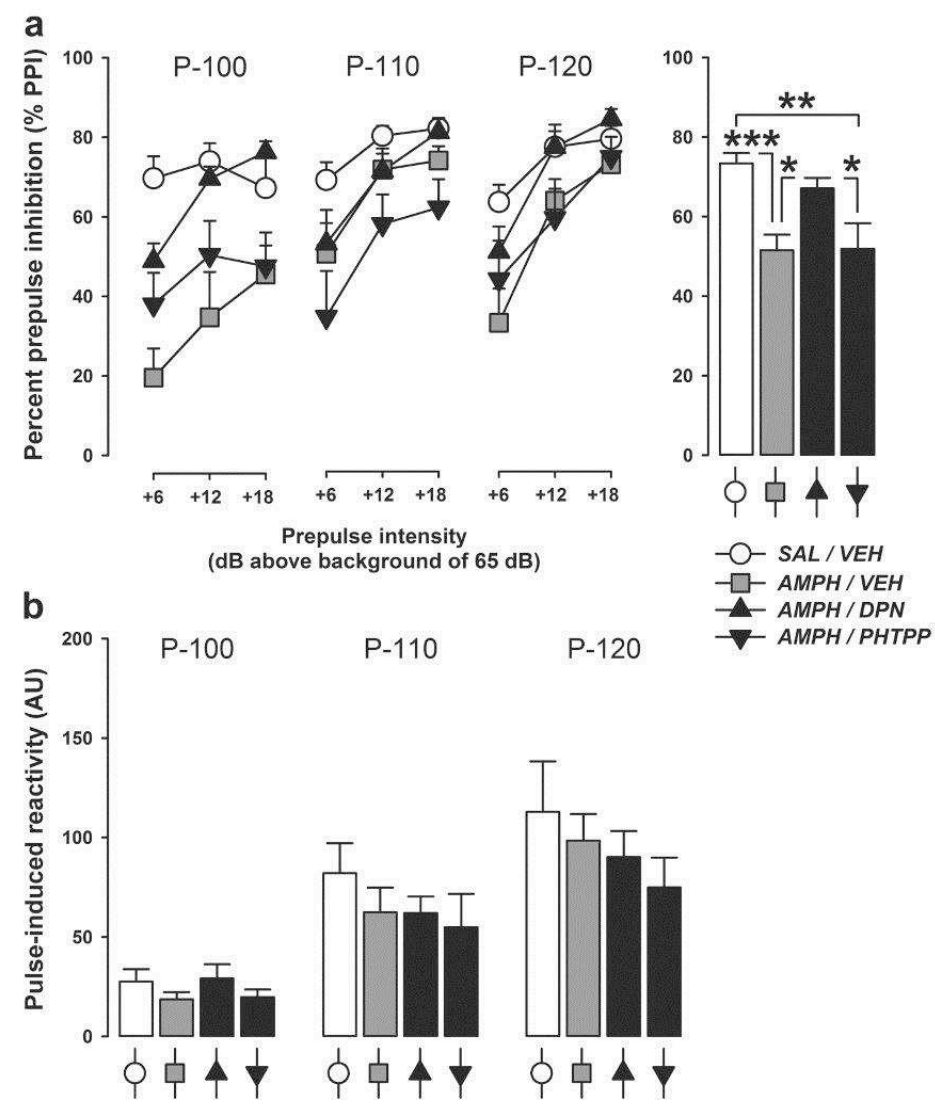

Figure 6. Effects of the ER- $\beta$ agonist DPN and antagonist PHTPP on amphetamine-induced PPI deficits. Mice were injected with vehicle (VEH), DPN (10 mg/kg body weight) or PHTPP ( $4 \mathrm{mg} / \mathrm{kg}$ body weight) $60 \mathrm{~min}$ prior to PPI testing, , followed by acute administration of saline (SAL) or amphetamine (AMPH, $4 \mathrm{mg} / \mathrm{kg}$ body weight) 50 min later, yielding 4 treatments groups: SAL/VEH, AMPH/VEH, AMPH/DPN, AMPH/PHTPP. (a) The line plot shows percent prepulse inhibition (\% PPI) as a function of the three distinct pulse levels (P-100, P-110, and P-120, which correspond to 100, 110 and $120 \mathrm{~dB}_{\mathrm{A}}$ ) and prepulse levels $\left(+6,+12\right.$ and $+18 \mathrm{~dB}_{\mathrm{A}}$ above background of $\left.65 \mathrm{~dB}_{\mathrm{A}}\right)$; and the bar plot depicts the mean \% PPI across all prepulse and pulse stimuli used. ${ }^{*} p<0.05,{ }^{* *} p<0.01$ and ${ }^{* * *} p<0.001$, based on post-hoc comparisons (b) The line plot shows startle reactivity (in arbitrary units, AU) to pulse-alone trials for the three different pulse levels. $N=8$ per group; all values are means \pm SEM. 


\section{Supplementary Results}
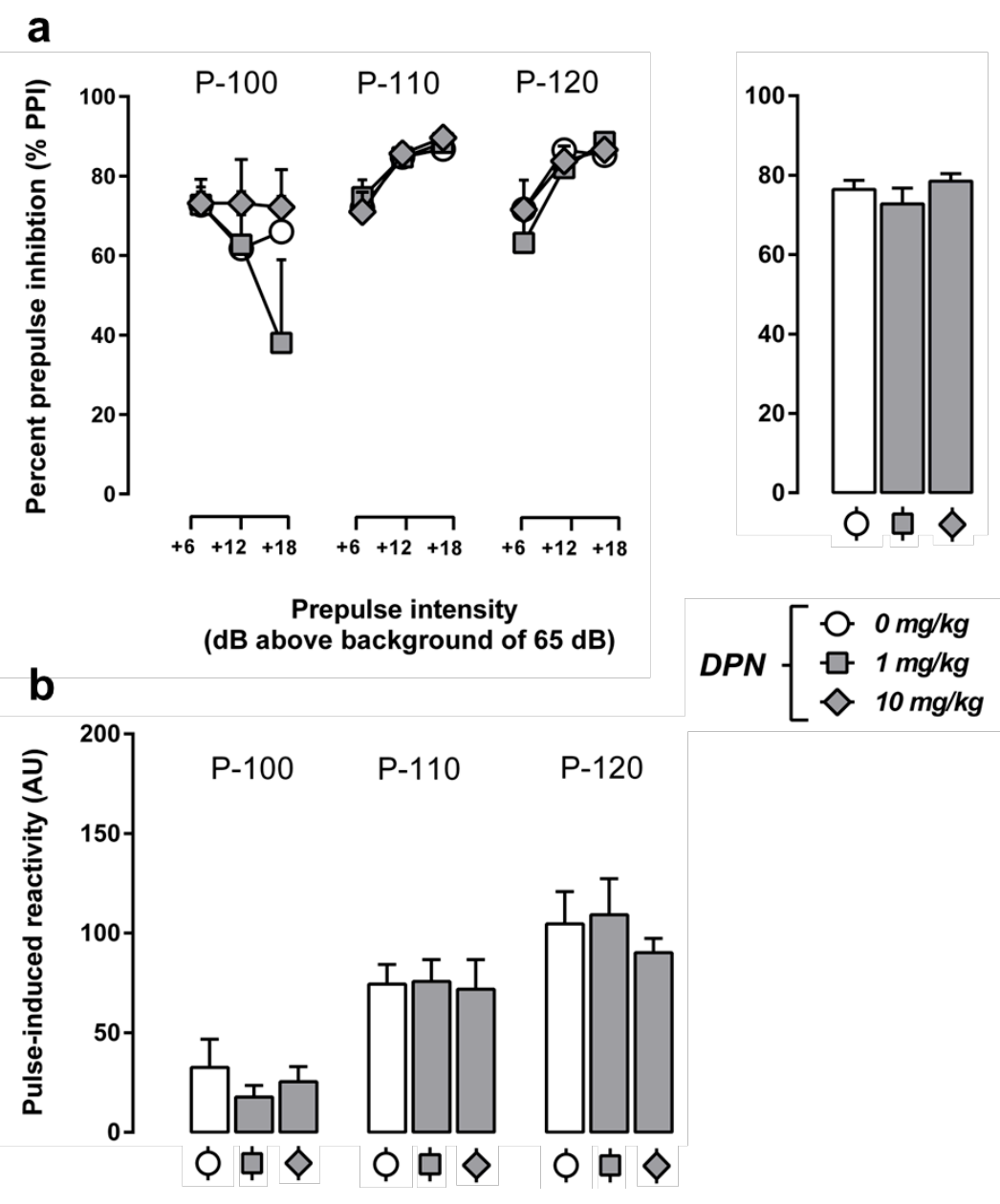

Supplementary Figure 1. Effects of the ER- $\beta$ selective agonist DPN on PPI after prior matching of pulse-induced startle reactivity levels among all three experimental groups. Mice were injected with vehicle (VEH; $=0 \mathrm{mg} / \mathrm{kg}$ ) or DPN at a low dose $(1 \mathrm{mg} / \mathrm{kg}$ body weight) or high dose (10 mg/kg body weight) $60 \mathrm{~min}$ before PPI testing. (a) The line plot shows percent prepulse inhibition (\% PPI) as a function of the three distinct pulse levels (P-100, P-110, and P-120, which correspond to 100, 110 and $120 \mathrm{~dB}_{\mathrm{A}}$ ) and prepulse levels $\left(+6,+12\right.$ and $+18 \mathrm{~dB}_{\mathrm{A}}$ above background of $\left.65 \mathrm{~dB}_{\mathrm{A}}\right)$; and the bar plot depicts the mean \% PPI across all prepulse and pulse stimuli used. (b) The graph shows startle reactivity (in arbitrary units, AU) to pulse-alone trials for the three different pulse levels. $\quad N=5$ per group (after excluding the 3 extreme responders in each experimental group for the purpose of matching pulse-induced startle reactivity levels); all values are means \pm SEM. 